\title{
Expression and Significance of CK5/6, P63, P40, CK7, TTF-1, NapsinA, CD56, Syn and CgA in Biopsy Specimen of Squamous Cell Carcinoma, Adenocarcinoma and Small Cell Lung Carcinoma
}

\author{
Expresión y Significado de CK5/6, P63, P40, CK7, TTF-1, NapsinA, CD56 Syn y CgA en Muestras de \\ Biopsia de Carcinoma de Células Escamosas, Adenocarcinoma y Carcinoma de Células Pequeñas de Pulmón
}

\author{
Jing-yuan Wang'; Xue-min Wang ${ }^{2}$; Xiao-yan Xu' ${ }^{1}$; Shi-rong Li ${ }^{1}$ \& Xiu-lan Liu ${ }^{1}$
}

WANG, J. Y. ; WANG, X. M.; XU, X. Y.; LI, S. R. \& LIU, X. L. Expression and significance of CK5/6, P63, P40, CK7, TTF-1, NapsinA, CD56 Syn and CgA in biopsy specimen of squamous cell carcinoma, adenocarcinoma and small cell lung carcinoma. Int. $J$. Morphol., 38(2):247-251, 2020.

SUMMARY: Nine tumor and various potential biomarkers were measured and combined the information to diagnose disease, all patients accepted fiber bronchoscopy brush liquid based cytologyand histopathology examination in order to reliably detect lung cancer. The samples from 314 Chinese lung cancer patients were obtained and CK5/6, P63, P40, CK7, TTF-1, NapsinA CD56,Syn and $\mathrm{CgA}$ were measured with the immunohistochemical SP method and analyzed correlation of the expression of these markers with pathological and clinical features of squamous cell carcinoma, adenocarcinoma, and small cell lung carcinoma. Squamous cell carcinoma, adenocarcinoma and small cell carcinoma were 61 cases, 114 cases and 139 cases,CK5/6 and P63 expression were more frequent in squamous cell carcinoma, with sensitivity and specificity of $77.05 \%$ and $96.44 \%, 83.61 \%$ and $88.93 \%$, and compared with adenocarcinoma and small cell carcinoma difference was statistically significant $(\mathrm{P}<0.05)$, The incidences of a positive $\mathrm{P} 40$ expression were $100 \%$ in squamous cell carcinoma, with specificity of $98.81 \%$.CK7, TTF-1 and NapsinA expression were more frequent in adenocarcinoma, with sensitivity and specificity of $85.09 \%$ and $78.69 \%, 79.82 \%$ and $93.44 \%, 56.14 \%$ and $95.08 \%$, and compared with squamous cell carcinoma and small cell carcinoma difference was statistically significant ( $\mathrm{P}<0.05)$. TTF-1, Syn, CgA and CD56 expression were more frequent in adenocarcinoma, with sensitivity and specificity of $86.33 \%$ and $93.44 \%, 89.21 \%$ and $98.36 \%, 74.10 \%$ and $100 \%, 96.40$ $\%$ and $96.72 \%$. The combined detection of CK5/6, P63 and P40 were more useful and specific in differentiating squamous cell carcinoma. CK7, TTF-1 and NapsinA were more useful and specific in differentiating lung adenocarcinoma. The impaired CD56, TTF-1, Syn and $\mathrm{CgA}$ reflects the progression of small cell lung cancer.

KEY WORDS: Lung cancer; Histopathology; Diagnostic value; Biomarkers.

\section{INTRODUCTION}

Lung cancer remains the most lethal cancer, and it is the leading cause of mortality of all cancers worldwide (Terry et al., 2010; She et al., 2013). The most common type of lung cancer is lung adenocarcinoma. In humans, squamous cell carcinoma is currently the second most frequent histologic subtype of lung cancer and is the leading subtype of lung cancer in China.With the development of molecular biology techniques as well as increased understanding of the mechanism of lung cancer, molecule targeted therapy or combined therapy gradually becomes the mainstream treatment, which requires pathologists to be able to accurately classify different types of lung cancer. Some cases of lung cancers can not be diagnosed by microscopic observation of histology and require additional confirmation by immunohistochemistry. Simulation studies suggest that CK5, p63, and p40 are commonly used immunohistochemical markers for squamous cell carcinoma, and napsin A (NAPA) and thyroid transcription factor 1 (TTF-1) are markers for adenocarcinoma of the lung. Syn and $\mathrm{CgA}$ are markers for small cell carcinoma of the lung cancer. Therefore, we performed immunohistochemistry testing on biopsy samples from 314 patients. Through the detection of expression of CK5/6, P63, P40, CK7, TTF-1, NapsinA CD56, Syn and CgA in squamous cell carcinoma, adenocarcinoma of lungs and small cell lung carcinoma. We aim to find a simple set of specific combination of antigens for the accurate diagnosis.

\footnotetext{
${ }^{1}$ Basic Medical College of Inner Mongolia Medical University, Hohhot, 010059, China.

${ }^{2}$ Prison of Hohhot, Hohhot010059, China.
} 


\section{MATERIAL AND METHOD}

Sample collection. Patients with lung cancers were recruited from First Hospital affiliated with Inner Mongolia Medical University during June. $1^{\text {st }}, 2013$ to Sept. $1^{\text {st }}, 2015$. Samples from 314 patients were collected, including 61 cases of squamous cell carcinoma of lungs, 114 cases of adenocarcinoma of lungs and 139 cases of small cell lung carcinoma. All patients have undergone histopathological examination.

Immunostaining. Biopsies were taken from the 314 patients with lung cancer at site where pathological changes occurred. After fixation, dehydration, embedding, slicing and Hematoxylin and Eosin (H\&E) staining, samples were observed under the microscope. SF methods were used for slice Immunohistochemistry. PBS was used as a negative control against primary antibodies and known positive adenocarcinoma of lungs, squamous cell carcinoma of lungs and small cell lung carcinoma were used as positive control. Antibodies (DakoCytomation and antibodies dilutions 1:100) for CK5/6, p63, P40, CK7,TTF-1. NapsinA, CD56, Syn and $\mathrm{CgA}$ were purchased form Maxim Biotechnology Development? Co. Ltd, using PV-9000 kit and DAB developing system. Slides were reviewed and analyzed by at least 2 pathologists. Diagnosis was chiefly based on histopathology results.

Results determination. Slides under going Immunohistochemical treatment demonstrated positive signals by showing yellow or brown particles. CK5/6, CK7, CD56, Syn and CgA are mainly expressed on cell membrane and cytoplasm; P63, P40 and TTF-1 are mainly expressed nucleus and NapsinA are mainly expressed in cytoplasm. Samples are considered negative if no stain is visible; (+) if less than $25 \%$ cells are stained; (++) if $25 \%$ to $75 \%$ cells are stained and (+++) if more than $75 \%$ cells are stained (Tables I and II).

Statistical methods. Data management and statistical analysis were performed using SPSS13.0 statistical software. One-way ANOVA with Bonferroni post hoc comparison. $\mathrm{P}<0.05$ is considered to be statistically significant.

\section{RESULTS}

The sensitivity and specificity of CK5/6, P63 in squamous cell carcinoma of lung cancer is $77.05 \%$ and 96.44 $\%, 83.61 \%$ and $88.93 \%$ respectively, which has statistical significance compared to adenocarcinoma of lungs and small cell lung carcinoma $(\mathrm{P}<0.01)$. The positive rate of $\mathrm{P} 40$ in squamous cell carcinoma of lungs is $100 \%$ nad tits specificity is $98.81 \%$. The sensitivity and specificity of CK7, TTF-1, NapsinA in adenocarcinoma of lung cancer are 85.09 $\%$ and $78.69 \%, 79.82 \%$ and $93.44 \%, 56.14 \%$ and $95.08 \%$ respectively. The positive expression rate of CK7 and TTF1 in squamous cell carcinoma of lungs, adenocarcinoma of lungs and small cell lung cancer is statistically significantly different $(\mathrm{p}<0.01)$. The sensitivity and specificity of TTF-1, Syn, CgA and CD56 in small cell lung cancer are $86.33 \%$ and $93.44 \%, 89.21 \%$ and $98.36 \%, 74.10 \%$ and $100 \%$, $96.40 \%$ and $96.72 \%$ respectively (Figs. 1, 2 and 3).

Table I. Immunophenotyping analysis of lung cancer.

\begin{tabular}{lccccccccc}
\hline Antibody & \multicolumn{3}{c}{ Squamous-cell carcinoma } & \multicolumn{3}{c}{ adenocarcinom } & \multicolumn{3}{c}{ Smallcell carcinoma of lung } \\
& + & - & Positive $\%$ & + & - & Positive $\%$ & + & - & Positive $\%$ \\
\hline CK7 & 13 & 24 & 35.14 & 97 & 1 & 98.98 & 8 & 6 & 57.14 \\
TTF-1 & 4 & 51 & 7.27 & 91 & 17 & 84.26 & 120 & 11 & 91.60 \\
P63 & 51 & 4 & 92.73 & 23 & 53 & 30.26 & 5 & 15 & 25.00 \\
CK5/6 & 47 & 3 & 94.00 & 6 & 84 & 6.67 & 3 & 16 & 15.79 \\
CD56 & 2 & 8 & 20.00 & 1 & 6 & 14.29 & 134 & 1 & 99.26 \\
Syn & 1 & 12 & 7.69 & 1 & 10 & 9.09 & 124 & 13 & 90.51 \\
P40 & 15 & 0 & 100.00 & 2 & 21 & 8.70 & 1 & 5 & 16.67 \\
napsinA & 3 & 25 & 10.71 & 64 & 16 & 80.00 & 0 & 8 & 0.00 \\
CgA & 0 & 9 & 0.00 & 0 & 11 & 0.00 & 103 & 30 & 77.44 \\
\hline
\end{tabular}

Table II. The clinicopathologic characteristics and Immunophenotyping analysis of SqCC,ADC, and scc.

\begin{tabular}{lcccccccrrr}
\hline & \multicolumn{2}{c}{ SqCC } & \multicolumn{4}{c}{ ADC } & \multicolumn{3}{c}{ scc } \\
& P63 & CK5/6 & P40 & CK7 & TTF-1 & napsinA & TTF-1 & Syn & CgA & CD56 \\
\hline Sensitivity \% & 83.61 & 77.05 & 24.59 & 85.09 & 79.82 & 56.14 & 86.33 & 89.21 & 74.10 & 96.40 \\
S pecifity \% & 88.93 & 96.44 & 98.81 & 78.69 & 93.44 & 95.08 & 93.44 & 98.36 & 100 & 96.72 \\
\hline
\end{tabular}


WANG, J. Y. ; WANG, X. M.; XU, X. Y.; LI, S. R. \& LIU, X. L. Expression and significance of CK5/6, P63, P40, CK7, TTF-1, NapsinA, CD56 Syn and CgA in biopsy specimen of squamous cell carcinoma, adenocarcinoma and small cell lung carcinoma. Int. J. Morphol., 38(2):247-251, 2020.

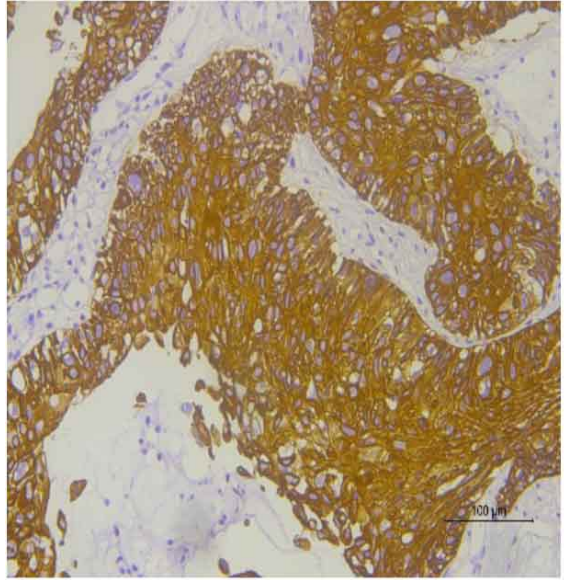

$\mathrm{CK} 5 / 6+(\mathrm{SP} \times 400)$

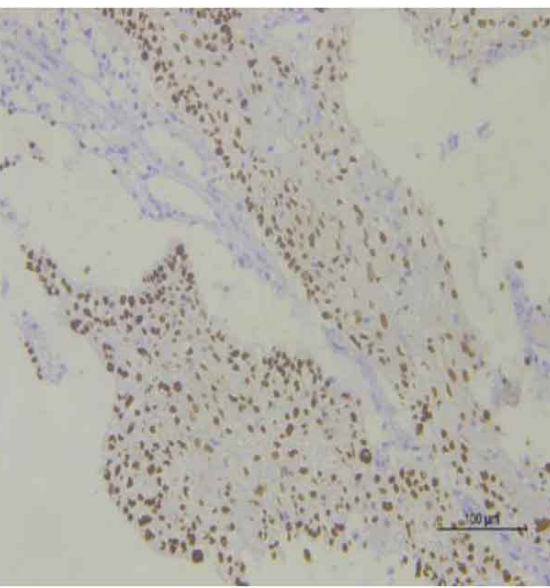

$\mathrm{P} 63+(\mathrm{SP} \times 400)$

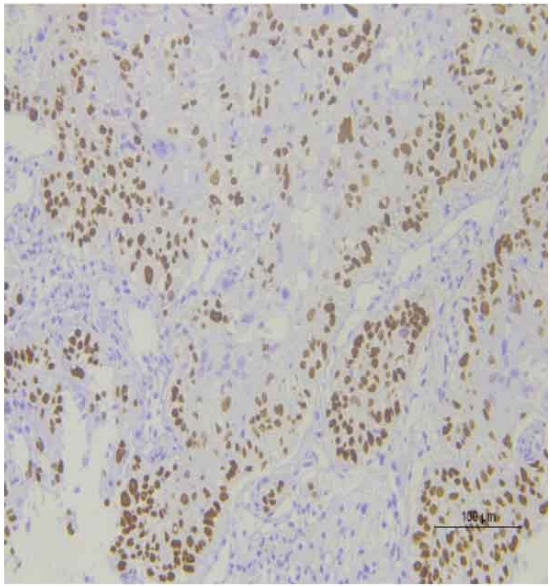

$\mathrm{P} 40+(\mathrm{SP} \times 400)$

Fig. 1. Immunostaining pattern of $\mathrm{CK} 5 / 6+$, P63+ and P40+ in squamous cell carcinomas.

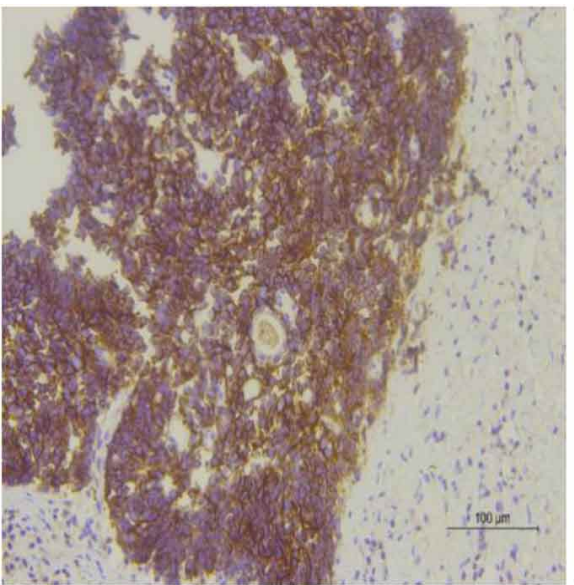

$\mathrm{CD} 56+(\mathrm{SP} \times 400)$

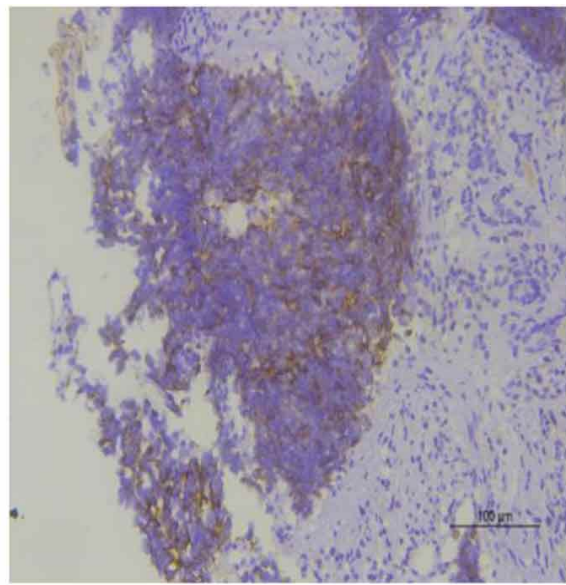

$\mathrm{CgA}+(\mathrm{SP} \times 400)$

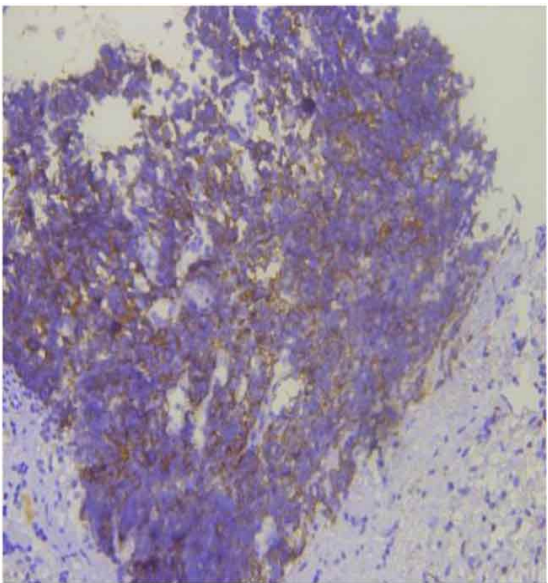

$\mathrm{Syn}+(\mathrm{SP} \times 400)$

Fig. 2. Immunostaining pattern of $\mathrm{CD} 56+, \mathrm{CgA}+$ and $\mathrm{Syn}+$ in small cell lung carcinomas.

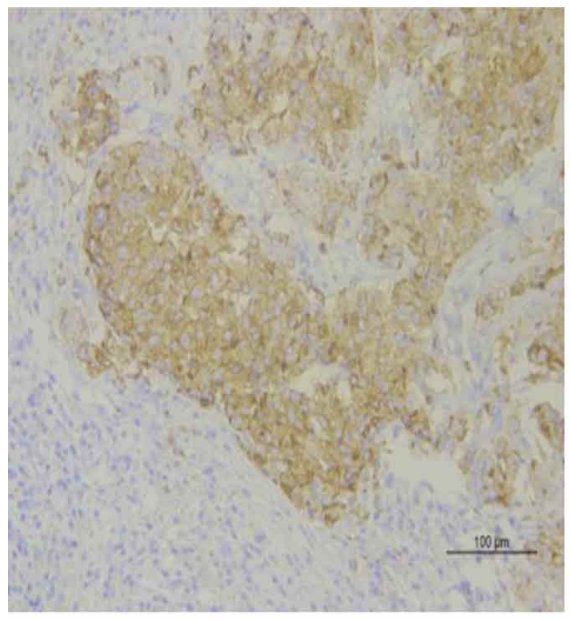

$\mathrm{Napsin} A+(\mathrm{SP} \times 400)$

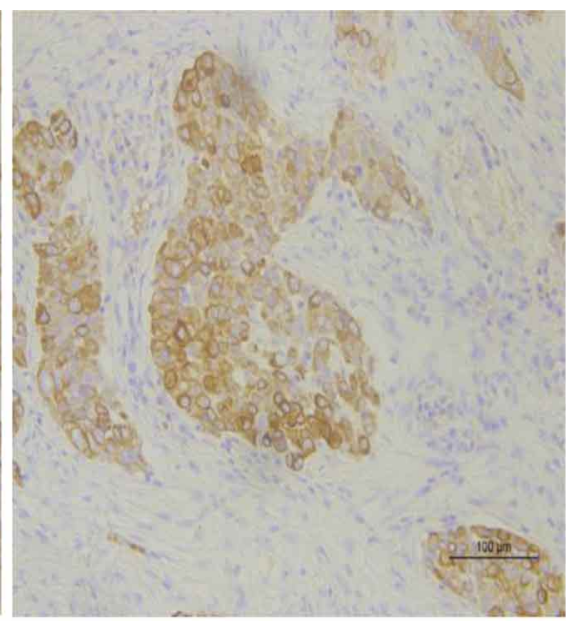

$\mathrm{CK} 7+(\mathrm{SP} \times 400)$

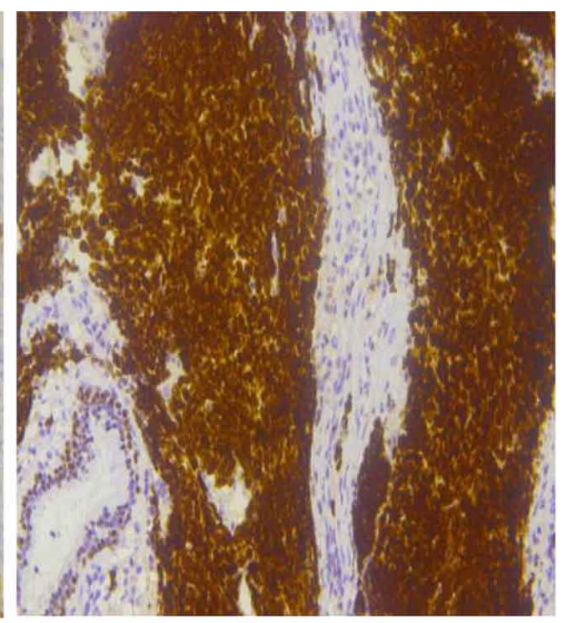

TTF-1+ $(\mathrm{SP} \times 400)$

Fig. 3. Immunostaining pattern of Napsin A+,CK7+ and TTF-1+ in adenocarcinoma. 


\section{DISCUSSION}

Traditional histological techniques include enzyme histology, immunohistochemistry, immunofluorescence, tissue microarray, in situ hybridization, fluorescence in situ hybridization, laser microanatomy, electron microscopy, etc. we performed immunohistochemistry testing on biopsy samples from 314 patients. Through the detection of expression of CK5/6, P63, P40, CK7, TTF-1, NapsinA, CD56, Syn and $\mathrm{CgA}$ in squamous cell carcinoma, adenocarcinoma of lungs and small cell lung carcinoma.

CK5/6 is a type of cell keratin mainly expressed on basal cells and spinous cells in skin, which however is rarely expressed in glandular epithelium. In our research, the sensitivity of diagnosing CK5/6 squamous cell carcinoma, adenocarcinoma of lungs and small cell lung carcinoma are $77.05 \%, 5.26 \%$ and $2.16 \%$, which is consistent with the 75 $\%-100 \%$ sensitivity reported in literature (Terry et al.; She et al.; Gurda et al., 2015). P63 is selectively expressed in epithelium basal cells with potential for differentiating into squamous epithelium and myoepithelial cells, therefore, it is plausible to use $\mathrm{P} 63$ as a marker to diagnose squamous cell carcinoma in lungs. Previous experiments have demonstrated that P63 is negative in small cell lung carcinoma and has a diagnosis sensitivity of $100 \%$ (Mukhopadhyay \& Katzenstein,2011; Ao et al., 2014). Our data show that the sensitivity and specificity of P63 for diagnosis of squamous cell carcinoma of lungs are $83.61 \%$ and $88.93 \%$ but the sensitivity and specificity of p63 for diagnosis of lung adenocarcinoma and the small cell lung carcinoma are low. This information corresponds to the positive rate of P63 in squamous cell carcinoma of lungs adenocarcinoma of lungs (93.8\% and $8.8 \%$ respectively) reported by literature (Brunnström et al., 2013). Therefore it is possible to use CK5/ 6 and P63 as individual markers for diagnosis of squamous cell carcinoma, adenocarcinoma of lungs and small cell lung carcinoma. In addition, P40 in our 315 samples showed a positive rate of $100 \%$ and is more specific in comparison with P63 and CK5/6. P40 had the highest accuracy in terms of diagnosing poorly-differentiated squamous carcinoma of lungs (Bishop et al., 2012). Combining the detection of Ck5/ 6 , P63 and P40 will possibly provide new diagnostic methods for differentiating between morphologically ambiguous poorly-differentiated squamous cell carcinoma of lungs and other cancer types.

CK7 is another type of cell keratin expressed in most normal glandular epithelium cells and transitional epithelium cells but it's not expressed in squamous epithelium (Kim et al., 2013). Our results show that the sensitivity and specificity of CK7 in adenocarcinoma of lungs are $85.09 \%$ and 78.69
\%. CK7's expression is low in squamous cell carcinoma of lungs and small cell lung carcinoma. In addition, the expression of CK7 is significantly different $(\mathrm{P}<0.01)$ in squamous cell carcinoma, adenocarcinoma of lungs and small cell lung carcinoma, which can facilitate the diagnosis of the three types of lung cancer. TTF-1 is a specific molecular marker of thyroid follicular epithelium and alveolar epithelium. Our data show that TTF-1 has high sensitivity and specificity in diagnosis of adenocarcinoma of lungs (79.82\% and $93.44 \%$ respectively). Also, TTF-1 expression is significantly different $(\mathrm{P}<0.01)$ in adenocarcinoma and squamous cell carcinoma of lungs, which can serve as sole immunological parameter for differentiating between the two pathological types. NapsinA is a member of aspartic proteinase family with high specificity, whose expression can be found positive in some TTF-1 negative poorlydifferentiated lung adenocarcinoma (She et al.). Our data show that NapsinA are positive in $56.14 \%$ adenocarcinoma in lungs with a specificity of $95.08 \%$ yet rarely positive in adenocarcinoma and squamous cell carcinoma of lungs. TTF1 was positive in 120 out of 139 cases small cell lung carcinoma while NapsinA was negative in all 139 cases of small cell lung carcinoma. Therefore, TTF-1 in conjunction with NapsinA will be contributive to the clinical diagnosis of adenocarcinoma of lungs and small cell lung carcinoma. Meanwhile, TTF-1 and NapsinA are more specific than CK7, while CK7 is more sensitive than TTF-1 and NapsinA in terms of diagnosis of adenocarcinoma of lungs. CK7 ,TTF-1 and NapsinA therefore can serve as immunological marker set for diagnosis of adenocarcinoma of lungs.

CD56, a type of cell adhesion molecules (CAM) is a glycoprotein mostly expressed in neurotoderm derived cells, tissue and tumor. It is a marker for diagnosis of neuroendocrine tumors. In our research CD56 had the highest sensitivity of $96.4 \%$ in terms of diagnosing small cell lung carcinoma. The expression of CD56 is higher in small cell lung carcinoma than other neuroendocrine markers, therefore, CD56 is a very stable protein marker (Wang et al., 2002). TTF-1 is a sensitive and specific immunologic marker for diagnosing lung cancer. In our experiment, TTF-1's sensitivity and specificity are 79.82 $\%$ and $93.44 \%, 86.39 \%$ and $93.44 \%$ in adenocarcinoma of lungs and small cell lung cancinoma respectively, which is in accordance with literature reports (Chhieng et al., 2001). The high sensitivity and specificity of TTF-1 in the adenocarcinoma of lungs and small cell lung carcinoma makes it a key molecular marker for diagnosing adenocarcinoma and small cell lung carcinoma but it cannot differentiate between these two types of lung cancer. Syn and $\mathrm{CgA}$ are traditional neuroendocrine immunological marker often used in diagnosis of neuroendocrine tumors (Kontogianni et al., 2005). Our results show that Syn and $\mathrm{CgA}$ have sensitivity and specificity of $89.21 \%$ and 98.36 
$\%, 74.1 \%$ and $100 \%$ respectively. The specificity is high but the sensitivity is low, corresponding to relevant research . Therefore, it possesses the potential of being assistive parameter. Summarizing the above, CD56, Syn and CgA all have relatively high specificity in small cell lung carcinoma and can be utilized in conjunction in clinical practice to improve the diagnosis accuracy of small cell lung carcinoma.

This paper examined the expression of immunological markers CK5/6, P63, P40, CK7, NapsinA, TTF-1, CD56, Syn and $\mathrm{CgA}$ in lung cancer tissues and discovered the clinical applicability of these antibodies to differentiate different types of lung cancer histopathology.

WANG, J. Y. ; WANG, X. M.; XU, X. Y.; LI, S. R. \& LIU, X. L. Expresión y significado de CK5/6, P63, P40, CK7, TTF-1, NapsinA, CD56 Syn y CgA en muestras de biopsia de carcinoma de células escamosas, adenocarcinoma y carcinoma de pulmón de células pequeñas. Int. J. Morphol., 38(2):247-251, 2020.

RESUMEN: Se midieron tumores y utilizaron nueve biomarcadores potenciales y se analizó la información para diagnosticar la enfermedad. A todos los pacientes se les realizó citología en líquido con broncoscopía de fibra y examen histopatológico para detectar de manera confiable el cáncer pulmonar. Se obtuvieron muestras de 314 pacientes chinos con cáncer de pulmón y CK5 / 6, P63, P40, CK7, TTF-1, Napsina A, CD56, Syn y CgA se midieron a través de histoquímica SP y analizaron la correlación de la expresión de estos marcadores con características patológicas y clínicas de carcinoma de células escamosas, adenocarcinoma y carcinoma de células pequeñas en el cáncer de pulmón. El carcinoma de células escamosas, el adenocarcinoma y el carcinoma de células pequeñas fueron 61 casos, 114 casos y 139 casos, respectivamente, la expresión de CK5 / 6 y P63 fueron más frecuentes en el carcinoma de células escamosas, con una sensibilidad y especificidad del 77,05\% y $96,44 \%, 83,61 \%$ y $88,93 \%$, y en comparación con el adenocarcinoma y el carcinoma de células pequeñas, la diferencia fue estadísticamente significativa $(\mathrm{P}<0,05)$. La incidencia de ap la expresión positiva P40 fue del $100 \%$ en el carcinoma de células escamosas, con una especificidad del 98,81\%. La expresión de CK7, TTF-1 y NapsinA fueron más frecuentes en el adenocarcinoma, con una sensibilidad y especificidad del 85,09\% y 78,69 \%, 79,82 \% y $93,44 \%, 56,14 \%$ y $95,08 \%$, y en comparación con el carcinoma de células escamosas y la diferencia de carcinoma de células pequeñas fue estadísticamente significativa $(\mathrm{P}<0,05)$.TTF-1, Syn, CgA y la expresión de CD56 fueron más frecuentes en adenocarcinoma, con sensibilidad y especificidad de $86.33 \%$ y $93.44 \%, 89.21 \%$ y 98.36 $\%, 74.10 \%$ y $100 \%, 96.40 \%$ y $96.72 \%$. La detección combinada de CK5 / 6, P63 y P40 fue más útil y específica en la diferenciación del carcinoma de células escamosas. CK7, TTF-1 y NapsinA fueron más útiles y específicos para diferenciar el adenocarcinoma de pulmón. El deterioro de CD56, TTF-1, Syn y CgA refleja la progresión del cáncer de pulmón de células pequeñas.

PALABRAS ClaVE: Cáncer de pulmón; Histopatología; Valor diagnóstico; biomarcadores.

\section{REFERENCES}

Ao, M. H.; Zhang, H.; Sakowski, L.; Sharma, R.; Illei, P. B.; Gabrielson, E.; Askin, F. \& Li, Q. K. The utility of a novel triple marker (Combination of TTF1, Napsin A, and p40) in the subclassification of non-small cell lung cancer. Hum. Pathol., 45(5):926-34, 2014.

Bishop, J. A.; Teruya-Feldstein, J.; Westra, W. H.; Pelosi, G.; Travis, W. D. \& Rekhtman, N. p40 (DNp63) is superior to p63 for the diagnosis of pulmonary squamous cell carcinoma. Mod. Pathol., 25(3):405-15, 2012.

Brunnström, H.; Johansson, L.; Jirström, K.; Jönsson, M.; Jönsson, P. \& Planck, M. Immunohistochemistry in the differential diagnostics of primary lung cancer: an investigation within the Southern Swedish lung cancer study. Am. J. Clin. Pathol., 140(1):37-46, 2013.

Chhieng, D. C.; Cangiarella, J. F.; Zakowski, M. F.; Goswami, S.; Cohen, J. M. \& Yee, H. T. Use of Thyroid Transcription Factor 1, PE-10, and Cytokeratins 7 and 20 in discriminating between primary lung carcinomas and metastatic lesions in fine-needle aspiration biopsy specimens. Cancer, 93(5):330-6, 2001.

Gurda, G. T.; Zhang, L.; Wang, Y.; Chen, L.; Geddes, S.; Cho, W. C.; Askin, F.; Gabrielson, E. \& Li, Q. K. Utility of five commonly used immunohistochemical markers TTF-1, Napsin A, CK7, CK5/6 and P63 in primary and metastatic adenocarcinoma and squamous cell carcinoma of the lung: aretrospective study of 246 fine needle aspiration cases. Clin. Transl. Med., 21(4):16, 2015.

Kim, M. J.; Shin, H. C.; Shin, K. C. \& Ro, J. Y. Best immunohistochemical panel in distinguishing adenocarcinoma from squamous cell carcinoma of lung: tissue microarray assay in resected lung cancer specimens. Ann. Diagn. Pathol., 17(1):85-90, 2013.

Kontogianni, K.; Nicholson, A. G.; Butcher, D. \& Sheppard, M. N. CD56: a useful tool for the diagnosis of small cell lung carcinomas on biopsies with extensive crush artefact. Clin. Pathol., 58(9):978-80, 2005.

Mukhopadhyay, S. \& Katzenstein, A. L. A. Subclassification of non-small cell lung carcinomas lacking morphologic differentiation on biopsy specimens: utility of an immunohistochemical panel containing TTF1, Napsin A, p63, and CK5/6. Am. J. Surg. Pathol., 35(1):15-25, 2011.

She, J.; Yang, P.; Hong, Q. \& Bai, C. Lung cancer in China: challenges and interventions. Chest, 143(4):1117-26, 2013.

Terry, J.; Leung, S.; Laskin, J.; Leslie, K. O.; Gown, A. M. \& Ionescu, D. N. Optimal immunohistochemical markers for distinguishing lung adenocarcinomas from squamous cell carcinomas in small tumor samples. Am. J. Surg. Pathol., 34(12):1805-11, 2010.

Wang, B. Y.; Gil, J.; Kaufman, D.; Gan, L.; Kohtz, D. S. \& Burstein, D. E. P63 in pulmonary epithelium, pulmonary squamous neoplasms, and other pulmonary tumors. Hum. Pathol., 33(9):921-6, 2002.

\section{Corresponding author:}

Xiu-lan Liu

Basic medical college of Inner Mongolia Medical University Hohhot 010059

CHINA

\section{E-mail: wangjingyuannmg@163.com}

Received: 25-06-2019

Accepted: 09-10-2019 